\title{
Exploring the preconception of the first year of medical students on medicine before entering medical school
}

\author{
Ye Ji Kang ${ }^{1}$, Jun Soo Hwang ${ }^{2}$, Yanyan Lin ${ }^{1}$, Hyo Jeong Lee ${ }^{3}$, Sang Yun $\mathrm{Han}^{4}$ and Do-Hwan Kim \\ ${ }^{1}$ Department of Medical Education, Hanyang University College of Medicine, ${ }^{2}$ Hanyang University College of \\ Medicine, ${ }^{3}$ Department of Education, Sangmyung University College of Education, and ${ }^{4}$ Department of Medical \\ Education, Seoul National University College of Medicine, Seoul, Korea
}

Purpose: First-year students can form a preconception based on life experiences before entering college and identifying learners' existing characteristics can be useful foundation data for curriculum development. This study examines what preconceptions freshman students had about medicine before entering medical school.

Methods: A total of 110 first-year students were asked about what preconceptions they had about "medicine". A total of 1,124 data were used in the content analysis method.

Results: The results were extracted into 5, and 12 twelve categories. On the theme of "scientific discipline", the knowledge students had about general health was based on scant expertise and little evidence. Students perceived medicine as Western and scientific, considering Korean traditional medicine as unscientific. Students believed that "medical practice" should be a "disease treatment" and "patient-centered" approach rather than a "social responsibility". In "the role of the doctor", students were concerned about the doctor's being financially stable on the positive side, and about the high-intensity workload on the negative side. In "medical education", students believed that studying medicine would be "hard and difficult" because of the "importance of memorizing" and "extensive study load". In "specialty stereotype", students had biases that were mostly concentrated on "psychiatry" and "surgery" Conclusion: Perception of "medicine" has been revealed to a varied range of themes, but some have been inaccurate or unrealistic. These prejudices and groundless beliefs have a gap with the learning outcomes that students should achieve in the curriculum, and these preconceptions seem to have been influenced by South Korea's unique cultural context.

Key Words: Preconception, Undergraduate medical education, Content analysis

\section{Introduction}

The first year of medical school is late adolescence or early adulthood. Students at this time of the year have partly formed identities, and their life experiences, including certain cultural, religious, and socio-economic status, determine this over the past 2 decades. In medical education, premedical period is particularly important because not only do they acquire medical knowledge, they also develop essential skills, attitudes, and form an identity for becoming future doctors [1].

In this respect, the medical humanity curriculum can be an important way. This curriculum may provide interdisciplinary coverage of humanities or social sciences that help to understand and practice medicine,
Received: July 23, 2021 • Revised: September 9, 2021 • Accepted: October 1, 2021 Corresponding Author: Do-Hwan Kim (https://orcid.org/0000-0003-4137-7130) Department of Medical Education, Hanyang University College of Medicine, 222-1 Wangsimni-ro, Seongdong-gu, Seoul 04763, Korea

Tel: +82.2.2220.0693 email: mededkimdh@hanyang.ac.kr
Korean J Med Educ 2021 Dec; 33(4): 369-379

https://doi.org/10.3946/kjme.2021.205

eISSN: 2005-7288

(C) The Korean Society of Medical Education. All rights reserved. This is an open-access article distributed under the terms of the Creative Commons Attribution Non-Commercial License (http:// creativecommons.org/licenses/by-nc/3.0/), which permits unrestricted non-commercial use, distribution, and reproduction in any medium, provided the original work is properly cited. 
not limited to biomedical knowledge in medical education. In order to operate the curriculum effectively, the outcome-based education that clearly sets the learning outcome that the curriculum must provide in advance and education accordingly must be preceded [2].

This study focuses on learners' preconceptions, based on the following reasons. First, exploring students' preconceptions can be a way of understanding student as beneficiaries of the education. Identifying learners' needs is a basic step that must be performed while designing a curriculum. This process is important because implementing education at the learner's level becomes possible. Additionally, it may increase learning motivation and thus, help teach classes more effectively [3]. Therefore, it is necessary to examine the perceptions and needs of students before they advance into medical school. Furthermore, it is crucial to examine whether the curriculum can meet their needs [4].

Moreover, learners' perceptions have a direct impact on learning achievement. Perceptions about the learning environment, or prior knowledge thereof, is a key element in determining students' academic achievement. Common misconceptions, such as prejudice and stereotypes, are likely to have a negative impact on students' education [5]. According to the cognitive theories of learning perspective, learning involved the active construction of meaning. In other words, cognitive theory argues that identifying learners' preconceptions helps learners build new knowledge on prior knowledge [6].

Several previous studies have examined how freshman medical students form their notions. According to these studies, students entered medical schools with preconceived notions about the social role of doctors and about what it means to become one. However, these beliefs were often inaccurate or unrealistic. Aggregated data showed that the students generally attained these ideas from television drama series [7,8]. These falsely biased perceptions are concerning because they may not be corrected during medical school. For example, in one study, one-third of the students had an anti-obesity bias, which did not improve by the time of their clerkship [9]. Similarly, other studies for example, on gender awareness [10], social determinants of health [11], relationship between identity formation and emotion [12], perception of professionalism [13], and perception of wellbeing [14] -have identified students' biases or preconceived notions. However, these previous studies only focus on identifying preconceptions on specific topics. These studies have limitations in showing which topics have stronger biases, and they do not fully discuss the relationships among these preconceptions.

This study focuses on South Korean students. Amid the prolonged economic downturn and severe job shortages, South Korea has high social aspirations for doctors and health care professionals who guarantee stable jobs. In this atmosphere, many students went to medical school at the recommendation of their parents, retried their entrance exams several times, and have grown up with intense academic competition, high performance pressure, and private education [15]. Therefore, tracking whether students can absorb the medical curriculum well, along with understanding their preconceived notions, is a sensitive task that must be undertaken when students enter college.

This study aimed to examine students' preconceptions about medicine before they entered medical school. It also sought to investigate the unique perceptions about medicine that exist within the South Korean cultural context.

\section{Methods}

This study was conducted on 110 first-year medical 
students who just entered Hanyang University College of Medicine in South Korea. To examine the perception of newly enrolled students, the survey was conducted in March when the semester just began. In the first week of the course, the researchers asked students to answer the question "What kinds of preconceptions (myths, beliefs, and stereotypes) do you have about medicine?" Students were expected to produce a 10-20 sentence response paper. The researchers then collected the students' responses as data for qualitative content analysis. Content analysis method is an analytical tool designed to provide a systematic approach for examining recorded textual data. It is widely used in both the medical and nursing fields. The content analysis method objectively classifies and systematically analyzes accumulated data [16].

The researchers processed the collected data through the code-category-theme from the inductive content analysis method [17]. First, the responses went through data cleaning to extract raw data. After collecting all student responses in an Excel file (Microsoft Corp., Redmond, USA), the researchers filtered out irrelevant answers. Second, they extracted keywords from the responses, which were set as "open codes". The researchers organized the open codes such that they retained as much of the original text as possible. Third, the researchers grouped the open codes that could be interpreted as belonging to similar contexts, into several sub-categories. The sub-categories related to the individual doctor's aspects could then be grouped to form the "individual" category. Lastly, by combining sub-categories, the researchers derived five final themes.

This study was approved by the Institutional Review Board of Institutional Review Board of Hanyang University (IRB approve no., HYU-2020-121). The need for consent was waived by the IRB. The authors confirm that all methods were performed in accordance with the relevant guidelines and regulations.

\section{Results}

Through content analysis, the researchers were able to derive five themes (scientific discipline, practice, doctor, medical education, and stereotype), 12 categories, and 38 sub-categories.

\section{Scientific discipline}

First year students perceived medicine as a "scientific discipline". This perception could be divided into three categories: knowledge, advancement, and nature (Table 1). The students mentioned the knowledge aspect most frequently. Such a category can be understood as the

\begin{tabular}{|c|c|c|c|}
\hline Variable & Category & Examples of statements & No. $|\%|$ \\
\hline Knowledge & $\begin{array}{l}\text { General health knowledge } \\
\text { and beliefs }\end{array}$ & $\begin{array}{l}\text { - Causes for catching a cold are a weak immune system and poor body } \\
\text { conditions } \\
\text { - Full body anesthesia makes one dumber. }\end{array}$ & 105 (9.3) \\
\hline \multirow[t]{2}{*}{ Advancement } & Continued advances & $\begin{array}{l}\text { - Medicine is always progressing. } \\
\text { - Medical technology will always evolve. }\end{array}$ & 37 (3.3) \\
\hline & Multidisciplinarity & $\begin{array}{l}\text { - Medicine is the integration of several studies }(+) \text {. } \\
\text { - Medicine is unrelated to physics }(-) \text {. }\end{array}$ & $34(3.0)$ \\
\hline \multirow[t]{2}{*}{ Nature } & Scientific nature of medicine & $\begin{array}{l}\text { - Medicine is based on quantitative data. } \\
\text { - All medicine is based on thorough objective and scientific judgment, and } \\
\text { not intuition. }\end{array}$ & $20(1.8)$ \\
\hline & $\begin{array}{l}\text { Unscientific nature of } \\
\text { traditional Korean medicine }\end{array}$ & $\begin{array}{l}\text { - Traditional Korean medicine is not scientific. } \\
\text { - Doctors do not like traditional Korean medicine practitioners. }\end{array}$ & $23(2.0)$ \\
\hline
\end{tabular}


achievement of the medical discipline. Most of these statements included such words as "cold", "obesity", and "alcoholic drinking", all of which are common health knowledge.

Students considered the development of medicine and predicted its continuous advancement. Many respondents believed that medicine was interconnected with other disciplines and required their cooperation to progress further. However, some students perceived medicine as an isolated discipline; one that had few connections with other fields of study. Responses included statements such as "Medicine is the integration of several studies," and "Medicine is unrelated to physics."

For freshman students, the word "scientific" defined the characteristics of medicine as a discipline. Although most students did not elaborate on the exact meaning of the term, some students defined it using phrases such as "based on quantitative data" or "excluding intuition". Furthermore, the respondents considered traditional Korean medicine "unscientific". In other words, when given the general term "medicine", students associated it with Western medicine. Students perceived Western medicine as relatively superior to traditional Korean medicine. However, very few stated why they perceived Korean medicine as unscientific.

\section{Practice}

The second theme was "practice" (Table 2). If "medicine as a scientific discipline" constituted the theoretical side, "medicine as a practice" pertained to the real world. Many freshman students described several ideal values that medical professionals should pursue in the real world. The students believed that medical practice should be conducted with "an attitude that

\begin{tabular}{|c|c|c|c|}
\hline Variable & Category & Examples of statements & No. $(\%)$ \\
\hline \multirow[t]{3}{*}{ Value } & Patient-centered & $\begin{array}{l}\text { - Medical professionals must prioritize patients and should not be affected by other } \\
\text { external factors. } \\
\text { - Doctors should treat not only the patient's body but also the patient's mind. }\end{array}$ & $55(4.9)$ \\
\hline & Respect for life & $\begin{array}{l}\text { - Doctors should prioritize life above other values. } \\
\text { - Medicine is a holy discipline as it deals with human life. }\end{array}$ & 39 (3.5) \\
\hline & Nondiscriminatory & $\begin{array}{l}\text { - Doctors should treat all patients equally, regardless of nationality, race, and religion, } \\
\text { among others. }\end{array}$ & 33 (2.9) \\
\hline \multirow[t]{3}{*}{ System } & Capitalistic society & $\begin{array}{l}\text { - Hospitals should operate as non-profit organizations } 1+1 \text {. } \\
\text { - Doctors over-treat for profits } 1-1 \text {. }\end{array}$ & $47(4.2)$ \\
\hline & Insurance system & $\begin{array}{l}\text { - Medical insurance system is a fair, well-made system. } \\
\text { - Market interventions are essential in licensing and the universal health insurance system. }\end{array}$ & $27(2.4)$ \\
\hline & $\begin{array}{l}\text { Healthcare } \\
\text { delivery system }\end{array}$ & $\begin{array}{l}\text { - Large hospital doctors are better. } \\
\text { - Secondary and tertiary medical institutions provide better diagnosis and treatment } \\
\text { than individual clinics. }\end{array}$ & $19(1.7)$ \\
\hline \multirow[t]{4}{*}{ (Un)certainty } & Fallibility & $\begin{array}{l}\text { - Medicine cannot be perfect because there are many exceptions }(-1 \text {. } \\
\text { - Doctors can treat patients perfectly without making any mistakes }(+1 \text {. }\end{array}$ & $47(4.2)$ \\
\hline & $\begin{array}{l}\text { Standardization of } \\
\text { diagnosis and } \\
\text { treatment }\end{array}$ & $\begin{array}{l}\text { - Same treatments should not be used every time because not all patients are the } \\
\text { same }(-1 \text {. } \\
\text { - Diseases are like mathematical problems; one can look at the conditions and logically } \\
\text { derive answers by using formulas }(+1 \text {. }\end{array}$ & 42 (3.7) \\
\hline & $\begin{array}{l}\text { Therapeutic and } \\
\text { side effect }\end{array}$ & $\begin{array}{l}\text { - Certain medicines can be used to cure specific illnesses } 1+1 \text {. } \\
\text { - Consuming a lot of medicine is not good for one's health } 1-1 \text {. }\end{array}$ & $30(2.7)$ \\
\hline & $\begin{array}{l}\text { Complexity of } \\
\text { medical practice }\end{array}$ & $\begin{array}{l}\text { - Some treatments can lead to unexpected results because the human body is complex }(+) \text {. } \\
\text { - Performing the same medical practice on a patient will lead to the same results }(-1 \text {. }\end{array}$ & $23(2.0)$ \\
\hline
\end{tabular}


respects life, and a patient-centered mind." Some examples of the students' responses are as follows: "Medical professionals must prioritize patients and should not be affected by any other external factors (patient-centered)," and "Doctors should prioritize life above other values (respect for life)."

The realization of these ideals is hindered by various systemic forces, such as overtreatment of patients (capitalism), inadequate medical fee system (insurance system), and discrimination in regional medical treatments (healthcare delivery system), among others. Despite the obstacles, some students believed that certain countries or hospitals have solved these practical problems and provided ideal medical care to its citizens. Examples of the students' responses include such statements as "The medical systems abroad (especially in the United States) are more ideal than South Korea."

Finally, many of the statements were related to the (un)certainty of medical practice, in which contradicting views existed. Some students pointed out that even the same medical treatments can lead to different results, because all patients are unique and medicine is not perfect. However, some students were highly confident about the predictability and general applicability of medical practice.

\section{Doctor}

The third theme, "doctor", presented the perceptions of students toward doctors, both as individuals and as a group (Table 3). As individuals, the students believed that becoming a doctor was sustainable because it guaranteed financial stability and physical health. However, some students were also concerned with the burnout caused by the "high-intensity workload" that did not guarantee "leisure time". Meanwhile, students described the characteristics of doctors, as a collective, using such words as "homogenous", "exclusive", and "hierarchical". Although statements about homogeneity contained both positive and neutral connotations, exclusivity and hierarchy carried mostly negative undertones. Some examples include "I thought every doctor had medical expertise and skill (homogeneous)," "Doctors form closed communities and interact only among themselves (exclusive)," and "Medical schools have a

\begin{tabular}{|c|c|c|c|}
\hline Variable & Category & Examples of statements & No. $|\%|$ \\
\hline \multirow[t]{3}{*}{ Individual } & Financial stability & $\begin{array}{l}\text { - Doctors lead a financially comfortable life. } \\
\text { - Medical professionals earn higher, on average, than other professions. }\end{array}$ & $39(3.5)$ \\
\hline & Risk of burnouts & $\begin{array}{l}\text { - Personal leisure time is not guaranteed for doctors. } \\
\text { - Medical professionals suffer from high-intensity workload. }\end{array}$ & 21 (1.9) \\
\hline & Physical well-being & $\begin{array}{l}\text { - Doctors live a healthy life because they know their medical knowledge. } \\
\text { - Doctors live a healthy life because they can prevent and diagnose any disease early on. }\end{array}$ & 20 (1.8) \\
\hline \multirow[t]{3}{*}{ Collective } & Homogeneous & - All students who enroll in medical schools want to become doctors. & $22(2.0)$ \\
\hline & Exclusive & $\begin{array}{l}\text { - Doctors form closed communities and interact only among themselves. } \\
\text { - Medicine is a difficult study for non-majors to approach. }\end{array}$ & $22(2.0)$ \\
\hline & Hierarchical & $\begin{array}{l}\text { - Doctors are in the professional position that can act authoritatively. } \\
\text { - Medical schools have a strong hierarchical relationship between their seniors and juniors. }\end{array}$ & $18(1.6)$ \\
\hline \multirow[t]{3}{*}{ Job } & Social respect & $\begin{array}{l}\text { - Being a doctor is a honorable and prestigious job. } \\
\text { - Doctors are socially successful people. }\end{array}$ & $25(2.2)$ \\
\hline & Outlook & $\begin{array}{l}\text { - Doctors have a stable career }(+) \text {. } \\
\text { - Doctors will soon be replaced by artificial intelligence }(-) \text {. }\end{array}$ & $23(2.0)$ \\
\hline & Curing diseases & $\begin{array}{l}\text { - Diseases are automatically cured by going to hospitals and getting treated by doctors. } \\
\text { - Doctors are aware of their patient's entire medical history. }\end{array}$ & $16(1.4)$ \\
\hline
\end{tabular}


strong hierarchical relationship between seniors and juniors (hierarchical).”

A third category called "Job" demonstrated that students viewed being a doctor as a socially "honorable" and "successful" job. However, very few students mentioned the doctors' responsibility toward "contributing to society" to meet these social expectations. Moreover, the role of "curing" individual patients from "diseases" was at the core of the students' perceptions of a doctor's job.

\section{Medical education}

Medical education may be largely categorized into "outcome" and "process" (Table 4). In terms of outcome, students described what was expected from doctors across various competencies. Excluding clinical competence, most attributes were related to soft skills, such as communication skills, professionalism, and altruism. Some examples from the responses are as follows: "Doctors require an attitude of self-sacrifice and working for others' happiness," and "Doctors should not give up on any patient and must see the patient until the end of the treatment."

In terms of the medical education process, the students did not have specific expectations. They had vague ideas, including "Memorizing is important," and "Medical study load is extensive."

\begin{tabular}{|c|c|c|c|}
\hline Variable & Category & Examples of statements & No. $|\%|$ \\
\hline \multirow[t]{8}{*}{ Educational outcome } & Altruism & $\begin{array}{l}\text { - Doctors require an attitude of self-sacrifice and work for the happiness } \\
\text { of others. } \\
\text { - Doctors should prioritize their patients' health above their own. }\end{array}$ & $36(3.2)$ \\
\hline & Responsibility & $\begin{array}{l}\text { - Doctors should not give up on any patient and should see them to the } \\
\text { end of their treatment. } \\
\text { - Doctors must have a huge sense of responsibility, regardless of their } \\
\text { medical practice results. }\end{array}$ & $31(2.8)$ \\
\hline & Clinical decision making & $\begin{array}{l}\text { - Doctors should judge rationally under any circumstances. } \\
\text { - Doctors should be aware of their capabilities and send patients to bigger } \\
\text { hospitals if the patient's symptoms are beyond their ability to treat. }\end{array}$ & $29(2.6)$ \\
\hline & $\begin{array}{l}\text { Cooperation with fellow } \\
\text { medical personnel }\end{array}$ & $\begin{array}{l}\text { - Doctors and nurses should cooperate with each other and recognize each } \\
\text { other's abilities and authorities }(+1 \text {. } \\
\text { - Individual competence is more important than cooperation with colleagues }(-) \text {. }\end{array}$ & $20(1.8)$ \\
\hline & $\begin{array}{l}\text { Mutual trust in } \\
\text { patient-physician } \\
\text { relationship }\end{array}$ & $\begin{array}{l}\text { - Doctor-patient relationship is important because patients trust and follow } \\
\text { doctors' words. } \\
\text { - Doctors can diagnose their patients accurately only when their patients } \\
\text { inform them of their symptoms. }\end{array}$ & $19(1.7)$ \\
\hline & Emotional detachment & $\begin{array}{l}\text { - Doctors need to be cool-headed and cold. } \\
\text { - Doctors are composed and cold, far from being kind. }\end{array}$ & $15(1.3)$ \\
\hline & $\begin{array}{l}\text { Communication (with } \\
\text { patients) }\end{array}$ & $\begin{array}{l}\text { - Communication ability is important for doctors because doctors must explain } \\
\text { to the patients their diseases. } \\
\text { - Doctors must tell their patients about worst-case scenarios as well. }\end{array}$ & $14(1.2)$ \\
\hline & Integrity & $\begin{array}{l}\text { - Doctors should not do anything that goes against their conscience when } \\
\text { treating patients. }\end{array}$ & $14(1.2)$ \\
\hline \multirow[t]{3}{*}{ Educational process } & $\begin{array}{l}\text { Emphasizing rote } \\
\text { memorization }\end{array}$ & $\begin{array}{l}\text { - Medical studies are mostly based on rote learning. } \\
\text { - Studying medicine requires good memory. }\end{array}$ & $29(2.6)$ \\
\hline & $\begin{array}{l}\text { Intensive and demanding } \\
\text { nature }\end{array}$ & $\begin{array}{l}\text { - A lot of studying is required to become a doctor, and it is tough. } \\
\text { - Medical students must enjoy themselves during the premedical period. }\end{array}$ & $25(2.2)$ \\
\hline & Lifelong learning & $\begin{array}{l}\text { - Medical studies require endless learning. } \\
\text { - The latest medical resources and studies must be studied constantly. }\end{array}$ & $14(1.2)$ \\
\hline
\end{tabular}


Table 5. Specialty Stereotype

\begin{tabular}{llll}
\hline Variable & Category & Examples of statements & No. (\%) \\
\hline Specialty & Psychiatry & - Most psychiatric treatments are conducted by psychological counseling. & 36 (3.2) \\
& & - Visitors to psychiatrics are weird. & 36 (3.2) \\
& Surgery & - Surgeons require dexterity with their hands. & 19 (1.7) \\
& Other specialties & - As surgeons, men are preferred over women. & - Men should not become obstetricians. \\
& & - Cardiothoracic surgeons must have a strong sense of duty and self-sacrifice.
\end{tabular}

\section{Specialty stereotype}

The final theme was on "specialty stereotypes" (Table 5). The majority of stereotypes were related to "psychiatry", and ranged across issues concerning patients, doctors, diseases, diagnosis, and treatments. Surgery was another sub-category that contained many stereotypes. However, unlike psychiatry, most of its contents were largely focused on surgeons. The students did not discern the various medical specialties (i.e., general surgery, orthopedics, and cardiothoracic surgery), and collectively referred to them as "surgery". The exception to this was plastic surgery, which the students named and used in the context of beauty.

\section{Discussion}

This study showed that students formed preconceptions across subject matters, and they can be categorized into five themes: scientific discipline, practice, doctor, medical education, and stereotype. Based on these findings, we posit the following discussions.

First, it is necessary to look at the difference between the learning outcome expected to be achieved during premedical period and the preconceptions that students formed before entering the medical school. The largest proportion of the collected data was health-related knowledge, which often had a low level of health common sense or ambiguous meaning that the reasons were not elaborately explained. In order to overcome the gap between the target educational performance and the current level of students and to set a proper direction for education, appropriate educational intervention and consensus are essential.

In particular, in the case of the premedical curriculum, which is noted in this study, this is the time for education to cultivate basic qualities to become a doctor before receiving a full-fledged medical education. The essence of the curriculum during premedical period is the convergence of humanities, social sciences, and natural sciences, and for this purpose, extensive liberal arts education in various fields and advanced education in core majors should be conducted in a balanced manner. Therefore, having a narrow view of a particular concept and phenomenon is bound to hinder effective premedical education [18].

For example, our results show that students already believed in various the stereotypes, concerning specific specialties at the time of admission. Especially, the students stated many of their beliefs on "psychiatry" and "surgery". From an educational standpoint, professors can use such dissonance between the learners' cognition and emotion to stimulate reflection and develop professional ideals [19]. Likewise, professors can use this discrepancy in various educational approaches to encourage change in students' attitude, impact, and behavior toward mental illnesses [20].

Previous studies suggest that prejudice against a 
department can become an important factor that influences students' future specialty choice. It is crucial to examine in advance students' preconceived notions about various departments because, depending on the degree, such notions may lead to differences in students' preferences for specific departments, level of contact with patients, and perceived intellectual excitement [21].

Furthermore, professors can use the results from identifying students' stereotypes on specialties to construct better career advice for young doctors. This can be done by understanding students' early career preferences [22]. In this aspect, it is important to detect and modify freshmen's biased and distorted views of medicine.

Second, it is essential to consider South Korea's unique social atmosphere and context. Students enter medical schools with preconceived notions about doctors and the expectations that come with the profession. At this point, an individuals' thoughts, perceptions, and beliefs share a deep connection with the social environment they lived in [23]. In South Korea, being a doctor is representative of high education and income. Many parents aspire for their children to become doctors. Such social aspiration leads to a fierce competition for medical school admission and private education [15]. Statements from the collected data demonstrate that students held positive beliefs toward doctors' social economic power and job security.

How students form perceptions can be interpreted in the historical context of Western medicine in South Korea. The South Korean medical education system has its roots in the Japanese-style Western medical education during the colonial period. After the Korean War and rapid economic development, the development of social practice of medical care or modern concept of ethics in Korean medicine was delayed during the 20th century, and instead, the influence of Japanese-style Western medical education, which considers medicine a concept of scientific discipline, remains strong. In this context, individuals of doctors were also recognized as successful self-employed people rather than professionals who considered public interest and patientcentered [24].

This historical background is evident in the students perceptions of doctors. Studies show that when students think of doctors, they think of personal safety more than social accountability such as financial stability, and physical well-being. In addition, the sub-category within the education outcome also highlighted aspects of "healer" rather than "professional". In other words, preconceptions remain in disease cure rather than holistic care.

At the same time, media such as movies, TV dramas, and internet websites can also influence the formation of students' perception. These factors reflect the cultural and social atmosphere of a country $[25,26]$. This study revealed that the students describe doctors as a group with words such as "exclusive" and "hierarchical". These results share some relation to the regular subjects of South Korean medical dramas that portray authoritative relationships during medical training processes and power struggles in hospitals. However, medical dramas depict fictional physicians. They sometimes present scenarios which are not true to the medical scene in reality. These dramas show unprofessional behaviors and attitudes that real doctors do not usually possess [27].

Interestingly, first year students viewed medicine as that of Western medicine and regarded Korean traditional medicine as unscientific. Previous literature showed that although medical students do think a lot about Korean traditional medicine, their understanding was not professional. As such, their view was negatively skewed [28].

These results may reflect the conflict prevalent between Korean traditional medicine and Western 
medicine. The conflict between doctors and Korean medicine doctors is intense, as doctors do not view Korean traditional medicine as an independent medical field like dentistry and pharmacology. The reason is that the two groups are in sharp conflict over their respective benefits on issues such as use of medical devices such as $\mathrm{X}$-ray and application of medical insurance. This may be an important point that should not be overlooked, since in designing curriculums, it is important to identify in advance South Korean students' preconceptions about medicine.

\section{Limitation}

Since the researcher conducted the study in a single medical school and cohort, the results are difficult to generalize. Future research should be conducted at more medical schools. In addition, future research should also track results in a single medical school in the longitudinal direction, as the characteristics of students entering the university may vary depending on the rapidly changing environment.

\section{Conclusions}

The first-year medical students seem to have various preconceptions about medicine. These preconceptions range broadly in subject matter, differing in discipline, practice, doctors, and education. A huge gap exists between the students' preconceptions of medicine and the expected learning outcomes from their premedical curriculum completion. The students' inaccurate understanding of health myths, medicine, and medical profession require academic attention. Unique social context, in the form of South Korean TV dramas and internet environment, influenced the biased perceptions of the students about the medical profession and the role of doctors. This study reveals the need for medical education experts to incorporate the understanding of first-year students' preconceptions when designing medical school curriculums.

\section{ORCID:}

Ye Ji Kang: https://orcid.org/0000-0003-1711-2394;

Jun Soo Hwang: https://orcid.org/0000-0002-7958-4330; Yanyan Lin: https://orcid.org/0000-0002-5758-0574;

Hyo Jeong Lee: https://orcid.org/0000-0001-8764-6610; Sang Yun Han: https://orcid.org/0000-0002-6174-1078; Do-Hwan Kim: https://orcid.org/0000-0003-4137-7130

Acknowledgements: None.

Funding: None.

Conflicts of interest: No potential conflict of interest relevant to this article was reported.

Author contributions: YJK and DHK developed the study concept and design. DHK acquired the data. YJK, JSH, SYH, and DHK analyzed the data. YJK and DHK interpreted the data and drafted the manuscript. YJK, YYL, HJL, and DHK contributed to the discussion. All authors read and approved the manuscript.

\section{References}

1. Cruess RL, Cruess SR, Boudreau JD, Snell L, Steinert Y. A schematic representation of the professional identity formation and socialization of medical students and residents: a guide for medical educators. Acad Med. 2015;90(6):718-725.

2. Jeon W. Suggestions for the improvement of medical humanities education. Korean Med Educ Rev. 2010; 12(1):23-31

3. Kern DE. A six-step approach to curriculum development. In: Thomas PA, Kern DE, Hughes MT, Chen BY, eds. Curriculum Development for Medical Education: A Six-Step Approach. 3rd ed. Baltimore, USA: Johns 
Hopkins University Press; 2016:5-9.

4. Goldie J. AMEE education guide no. 29: evaluating educational programmes. Med Teach. 2006;28(3):210224.

5. Ramsden P. Learning to teach in higher education. London, UK: Routledge; 2003.

6. Wilkerson L, Irby DM. Strategies for improving teaching practices: a comprehensive approach to faculty development. Acad Med. 1998;73(4):387-396.

7. Kay D, Berry A, Coles NA. What experiences in medical school trigger professional identity development? Teach Learn Med. 2019;31(1):17-25.

8. Fraser SJ, Al Youha S, Rasmussen PJ, Williams JG. Medical student perception of plastic surgery and the impact of mainstream media. Plast Surg (Oakv). 2017; 25(1):48-53.

9. Miller DP Jr, Spangler JG, Vitolins MZ, et al. Are medical students aware of their anti-obesity bias? Acad Med. 2013;88(7):978-982.

10. Andersson J, Verdonk P, Johansson EE, Lagro-Janssen T, Hamberg K. Comparing gender awareness in Dutch and Swedish first-year medical students: results from a questionaire. BMC Med Educ. 2012;12:3.

11. Holden AC, Leadbeatter D. Conceptualisations of the social determinants of health among first-year dental students. BMC Med Educ. 2021;21(1):164.

12. Stubbing E, Helmich E, Cleland J. Authoring the identity of learner before doctor in the figured world of medical school. Perspect Med Educ. 2018;7(1):40-46.

13. Park SY, Shon C, Kwon OY, Yoon TY, Kwon I. A qualitative thematic content analysis of medical students' essays on professionalism. BMC Med Educ. 2017;17(1): 79.

14. Byrnes C, Ganapathy VA, Lam M, Mogensen L, Hu W. Medical student perceptions of curricular influences on their wellbeing: a qualitative study. BMC Med Educ. 2020;20(1):288.
15. Park JH, Kim KH, Jun HR, Lee JY. A national sample survey of medical students about their perception and evaluation on medical study, career plan, and medical care system: part 1. survey methods and characteristics of sample. Korean J Med Educ. 1999;11(2):339-363.

16. Hawick L, Cleland J, Kitto S. Sending messages: how faculty influence professionalism teaching and learning. Med Teach. 2017;39(9):987-994.

17. Graneheim UH, Lundman B. Qualitative content analysis in nursing research: concepts, procedures and measures to achieve trustworthiness. Nurse Educ Today. 2004;24(2):105-112.

18. Kim YI, Yoon SD, Ahn YO, Ko YW. Development of educational program for premedical course. Seoul, Korea: Korean Council for University Education; 1992.

19. Thompson BM, Teal CR, Rogers JC, Paterniti DA, Haidet P. Ideals, activities, dissonance, and processing: a conceptual model to guide educators' efforts to stimulate student reflection. Acad Med. 2010;85(5):902-908.

20. Petkari E, Masedo Gutiérrez AI, Xavier M, Moreno Küstner B. The influence of clerkship on students' stigma towards mental illness: a meta-analysis. Med Educ. 2018; 52(7):694-704.

21. Schlesinger AE, Blane CE, Vydareny KH. First-year medical students' attitudes toward radiology. Invest Radiol. 1992;27(2):175-178.

22. Cleland J, Johnston PW, French FH, Needham G. Associations between medical school and career preferences in year 1 medical students in Scotland. Med Educ. 2012;46(5):473-484.

23. Reimer D, Russell R, Khallouq BB, et al. Pre-clerkship medical students' perceptions of medical professionalism. BMC Med Educ. 2019;19(1):239.

24. Ahn D. Development of medical professionalism in South Korea. J Korean Med Assoc. 2011;54(11):11371145.

25. Czarny MJ, Faden RR, Nolan MT, Bodensiek E, 
Sugarman J. Medical and nursing students' television viewing habits: potential implications for bioethics. Am J Bioeth. 2008;8(12):1-8.

26. Weaver R, Wilson I. Australian medical students' perceptions of professionalism and ethics in medical television programs. BMC Med Educ. 2011;11:50.

27. Czarny MJ, Faden RR, Sugarman J. Bioethics and professionalism in popular television medical dramas. J Med Ethics. 2010;36(4):203-206.

28. Huh NW, Jeong SA, Kim SJ, Mok NR, Park HW, Shin HK. Attitude and recognition of medical school students on Korean traditional medicine diagnosis and treatment. Korean J Orient Prev Med Soc. 2013;17(1):107-116. 